Yüzüncü Yil Üniversitesi
Tarim Bilimleri Dergisi

Araştırma Makalesi (Research Article)

\title{
Hızlı Büyüme Potansiyeline Sahip Yerleşim Alanlarının Detaylı Toprak Etütleri ve Arazi Değerlendirmeleri: Mustafalar Köyü Örneği, Adana**
}

\author{
Bayram Çağdaş DEMIREL ${ }^{* 1}$, Suat ŞENOL ${ }^{2}$ \\ ${ }^{1}$ Akdeniz Üniversitesi, Ziraat Fakültesi, Toprak Bilimi ve Bitki Besleme Bölümü, 07070, Antalya, Türkiye \\ ${ }^{2}$ Çukurova Üniversitesi, Ziraat Fakültesi, Toprak Bilimi ve Bitki Besleme Bölümü, 01330, Adana, Türkiye \\ *Sorumlu yazar e-posta: cagdasdemirel@akdeniz.edu.tr
}

\section{Makale Bilgileri}

Geliș: 19.09 .2019

Kabul: 05.12.2019

Online Yayinlanma 31.12.2019

DOI: 10.29133/yyutbd.622099

\section{Anahtar kelimeler}

Detaylı toprak etüdü, Mustafalar köyü arazi Kullanım planı,

Nazım imar planı altlı̆̆ı.
Öz: Gelișen dünyada hızla artan nüfus kentsel alan ihtiyacını arttırmıs ve tarımsal arazileri daha çok tehdit eder hale gelmiştir. Adana ili 19. yüzyılın sonlarında Çukurova'nın tarıma açılmasıyla daha sonra da sanayileşme ve kırsaldan kente göçlerin devam etmesiyle, son 30 yilda 5 kat büyüme göstermiștir. Adana ilinin Mustafalar köyündeki bu çalıșmada, karar vericilerin artan kentsel alan ihtiyaçlarını karşılarken, doğal kaynakları koruyarak, ideal arazi kullanım şekillerine uyabilmeleri için, altlık olarak kullanabilecek, detaylı toprak etütleri ve arazi değerlendirme çalışmaları yapılmıştır. Mustafalar köyü ve çevresinde 1.732 hektarlık alanda gerçekleştirilen çalışmada, 8 farklı toprak serisi tespit edilmiş ve bu toprak serileri Toprak Taksonomisine göre Alfisol, Inceptisol ve Entisol ordolarında sınıflandırılmıştır. Çalışma alanında yapılan analizler ve tanımlamalar sonucunda; toprakları \%71.67'sinin kireçli ve çok kireçli (\%7-25), \%50'den fazlasının ince bünyeli kil tekstürde, \% 61'inin sı̆̆ derinlikte $(0-30 \mathrm{~cm})$, ve \%48'inin eğimli veya çok dik eğimli $(\% 12+)$ olduğu belirlenmiştir. Yapılan toprak etüd-haritalama ve değerlendirme çalışmaları sonucunda da; Detaylı Temel Toprak Haritası, Arazi Yetenek Sinıflaması Haritas1, 5403 Sayılı Toprak Koruma ve Arazi Kullanımı Kanunu (TKAKK)'na göre sınıflama Haritası ve Potansiyel Kullanım Haritası oluşturulmuștur. Oluşturulan bu haritalardan çalışma alanında en fazla \%55 oranla VI. sınıf araziler bulunurken yine bu alandaki arazilerin TKAKK' ya göre \%84'ü Marjinal Tarım Arazisi, \%11'i Mutlak Tarım Arazisi ve \%5'i Tarım Dıșı Arazi olarak sınıflandııılmıştır. Ayrıca Mustafalar köyü ve çevresinde gelecek yıllardaki 3 aşamalı arazi kullanımı önerisi haritaları oluşturulmuştur.

\section{Detailed Soil Survey and Site Assessments of Urban Areas with Rapid Growth Potential: Case Study of Mustafalar, Adana}

\section{Article Info}

Recieved: 19.09.2019 Accepted: 05.12.2019

Online Published 31.12.2019

DOI: 10.29133/yyutbd.622099

Keywords

Detailed Soil Survey and Mapping, Land Use Plan of Mustafalar Village, The master plan
Abstract: In the developing world with the rapidly increasing population, the need for resettlement area has increased and the agricultural land has become more threatened. Because of beginning irrigated agriculture in the Çukurova plain in the late 19th century, with continued industrialization and rural-urban migration, Adana has grown in population 5 times in the last 30 years. This study, carried out in the village of Mustafalar in Adana province, detailed soil surveys and land evaluation studies were for development of master plans. Mustafalar village and surrounding areas, covers an area of 17320 decares. 8 different soil series were described in the survey area and these soil series were classified according to Soil Taxonomy as Alfisol, Inceptisol and Entisol. As a result of soil survey and mapping studies; Detailed Basic Land Map, Land Capability Classification Map, Agricultural Land Classification Map according 
to Law No. 5403 on Soil Protection and Land Use and Potential Usage Map of the study area have been created. In the survey area, according to Land Capability Classification IV. and VI. Class land are covering \%77 of the total land, according to Law No. 5403 on Soil Protection and Land Use, Marginal Agricultural Land rate was found \% 50 and Non-Agricultural Land rate was found \% 42. In addition, 3 level maps of land use proposals for the next years in the village of Mustafalar and surrounding areas were created.

** Yüksek Lisans Tezinden türetilmiştir.

\section{Giriş}

Dünya 20. yüzyıldan bu yana hızlı bir şekilde nüfus artışı yaşamaktadır. 1950' li yılların ilk yarısına kadar yaklaşık 2.7 milyar olan dünya nüfusu günümüzde 7,4 milyarı çoktan geçmiş hatta 2050 yılına kadar bu rakamın 10 milyarı bulması tahmin edilmektedir (Worldometers, 2016). Özellikle 20. yüzyılın son 20 senesinde dünya nüfusu en fazla yükselişi göstermiştir. Artan nüfusla birlikte ihtiyaçlar ve talepler de aynı şekilde her geçen gün artmakta ve bunlar da çeşitli sorunları beraberinde getirmektedir. Gelişmiş ve gelişmekte olan ülkelerde hızla ilerleyen sanayileşme, giderek azalan ve yok olma tehlikesi ile karşı karşıya kalan dünyamızın doğal kaynakları ve bütün bunların yanında katlanarak artan dünya nüfusu, gelecek konusunda çevresel endişeleri arttırmaktadır. Doğal kaynaklar üzerindeki insan baskısını azaltmak ve doğru arazi kullanımını tekniklerini tanımlamak için, bilimsel esaslı arazi değerlendirme çalışmalarının yürütülmesi gereklidir (AbdelRahman ve ark., 2016). Toprağın korunması, sürdürülebilir kullanılması ancak özelliklerinin iyi belirlenmesi, haritalanması ve veri tabanı oluşturulması ile birlikte gerekli planların uygulanmasıyla mümkün olacaktır (Topçu, 2012). Çünkü toprak ve arazi özelliklerinin detaylı olarak tanımlanması sürdürülebilir arazi yönetimlerinin temelidir (Çelik A., Akça E., 2017).

Toprak kaynaklarına olan ihtiyaçların artması dünyadaki birçok ülke topraklarını detaylı olarak haritalayarak, toprakları yeteneklerine göre kullanma gereğini doğurmuştur (Çullu, 2012). İhtiyaçların giderek artması ve çeşitlenmesi sonucunda kaynaklar üzerinde oluşan baskı, yanlış arazi kullanımını da beraberinde getirerek, arazi varlıklarının tahrip edilmesine ve yoksulluk başta olmak üzere çok çeşitli sosyal problemlerin yaşanmasına zemin hazırlamaktadır (FAO, 1976).

Ülkemizdeki 5403 sayılı Toprak Koruma ve Arazi Kullanım Kanunundaki bazı açıklıklar arazilerin doğru şekilde kullanılması konusunda eksikliklere sebebiyet vermektedir. Bu yüzden en verimli araziler yerleşim alanı ve sanayi alanı olarak kullanılmakta, öte yandan da ormanlar ve meralardan tarlalar açılarak tarım alanı kazanılmaya çalışılmaktadır (Akten, 2008). Arazi kullanımın kararlarının doğal kaynaklara kalıcı zararlar vermeyecek şekilde alınabilmesi için arazi kullanım planlarının yapılması ve uygulamaya konulmasını gerektirmektedir (Şenol, 2010). Böylesi plansız bir şekilde devam eden ve tehditlere açık olan bir sistemin uzun ömürlü ve sürdürülebilir olması düşünülemez.

Toprağın vazgeçilemez ve sınırlı üretim faktörlerinden biri olması nedeniyle tarım dışı kullanımlarının önlenebilmesi için, topraklarımızın yetenek ve niteliklerinin belirlenmesi, Arazi Kullanım Planlamasının yapılması bir zorunluktur (Topçu, 2012). Ayrıca mevcut toprak haritaları gözden geçirilerek, ülkemizdeki bütün tarım arazilerine yönelik Arazi Kullanım Planlarının ivedilikle hazırlanması gereklidir. Hızlı ve kontrol dışı kentleşmenin tarım arazilerini tehdit etmeye başladığı alanlarda geri dönüşümü olmayan arazi kullanımlarının oluşmaması adına tarımsal nitelikli, mera ve orman alanların korunması sürdürülebilir bir arazi yönetimi için önemlidir (Yakar, 2013). Ülkemizde kentsel alanlarda arazi kullanımları, imar planları ile belirlenmekte ve buna göre uygun araziler oluşturulmaktadır. Hangi alanlar konut alanları, hangi alanlar kamu tesis alanları, nereler yol ve yeşil alanlar bu planlarla belirlenmektedir. Ancak planlama aşamasında plana esas veri eksikliğinden kaynaklı ideal planlar oluşturulamamaktadır (Yakar, 2013)

İşte bu çalışmada, şehirleşmenin ve sanayi kuruluşlarının, kontrolsüz bir şekilde tehdit etmeye başladığı, mera, orman ve tarımsal arazilerin yoğun olarak bulunduğu, Adana ilinin Sarıçam ilçesine bağlı Mustafalar köyü ve çevresinde detaylı toprak etüt - haritalama ve arazi değerlendirme çalışmaları yapılmıştır. Yereldeki karar vericilerin arazi kullanımı hakkında alacakları karalarda, elde edilen bu bilgileri altlık olarak kullanmaları çalışma alanı için en doğru kullanım kararlarını almaları amaçlanmıştır. 


\section{Materyal ve Yöntem}

\subsection{Materyal}

Çalışma Adana iline bağlı Sarıçam ilçesinin $3707^{\prime} 57.31$ " ve $3705^{\prime} 44.45^{\prime \prime}$ kuzey enlemleri ve 35029'17.62" ve 35032'8.97" doğu boylamları arasında kalan alanda gerçekleştirilmiştir (Şekil 1). Çalışma Mustafalar köyünün gelecekteki büyüme potansiyeli dikkate alınarak Mustafalar köyü ve çevresindeki 1732 ha'lık alanda yürütülmüştür.

Çalışmada altlık kartografik materyal olarak 17.08.2014 tarihli Quickbird uydu görüntüleri ve SPOT-5 uydusunun Google Earth uygulamasındaki görüntüleri kullanılmıştır. Bununla beraber, çalışma alanına ait Harita Genel Komutanlığından elde edilen 1:25.000 ölçekli standart topoğrafik harita, Maden Tetkik Arama Enstitüsü'nden (MTA) elde edilen 1:25.000 ölçekli jeoloji haritası ve Adana Meteoroloji Bölge Müdürlüğünden alınan iklim verileri kullanılmıştır. Ayrıca Köy Hizmetleri Genel Müdürlüğü tarafindan yapılmış olan Adana İli Arazi Varlığı Raporu da (Tarım Orman ve Köyişleri Bakanlığı, 1996) diğer yardımcı kartografik materyal olarak kullanılmıştır.

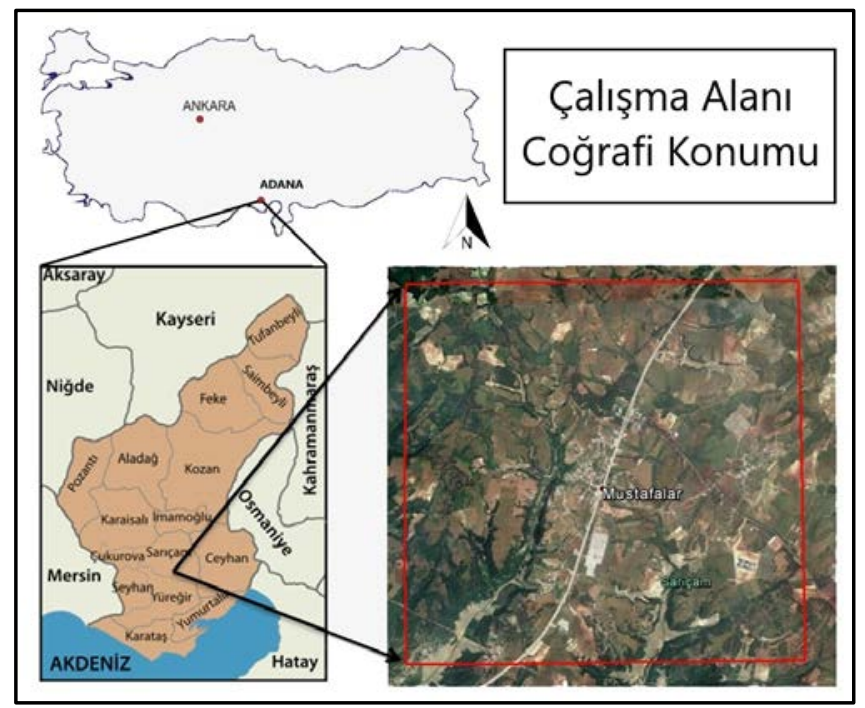

Şekil 1. Çalışma alanı coğrafi konumu.

Mustafalar köyü, Adana ilinin kuzeydoğusunda, il merkezine $20 \mathrm{~km}$ ve Sarıçam ilçesine 12 km uzaklıkta bulunmaktadır. Çalışma alanında Mustafalar köyünün yanı sıra Kızılkaş, Kılıçlı, Aydınyurdu, Yeniyayla, Gökbuket köylerinin bir bölümü yer almaktadır. 1732 ha' lık çalışma alanının 55 ha' 1 tarım dışı (yerleşim yerleri, kamu tesisleri, özel tesisler vb.) arazilerden oluşmaktadır. Çalışma alanında Buğday, Arpa, Turunçgiller, Nar ve Zeytin yetiştiriciliği yapılan önemli tarımsal ürünlerdendir. Çalışma alanında toplamda yaklaşık 425 ha çam ormanın yanı sıra yaklaşık 21 ha kadar kültüre alınmış zeytin bahçesi bulunmaktadır. Bunların dışında kalan 1230 ha' lık alan ise diğer tarımsal faaliyetlerin bulunduğu alanlar olarak kullanılmaktadır. Çalışma alanında tipik Akdeniz İklimi hüküm sürmektedir. Yağışların yarısı kış aylarında diğer yarısı da ilkbahar ve sonbaharda görülmektedir. Yaz aylarında 2-3 ay yăğş düşmemektedir. Çalışma alanı toprak nem rejimi Xeric olarak belirlenmiştir. Yıllık ortalama toprak sıcaklığının $50 \mathrm{~cm}$ derinlikte $21.1^{\circ} \mathrm{C}$ olması nedeniyle toprak sıcaklık rejimi Thermic olarak belirlenmiştir. MTA'dan elde edilen verilere göre 2 farklı jeolojik yapı bulunmaktadır. Alansal dağılım olarak en fazla görülen jeolojik yapı pliyosen yaşta karasal kırıntılardır. Çalışma alanındaki diğer jeolojik yapı ise kuvarterner yaşta travertenlerdir.

\subsection{Yöntem}

Çalışma alanı temel toprak haritasında, haritalama ünitesi olarak, toprak serileri ve bu toprak serilerinin üst toprak tekstürü, eğim, taşlılık, derinlik fazları esas alınmıştır. Haritalama ünitesi olarak toprak serilerinin seçilmesinin nedeni doğal toprak sınıflama sistemi içerisinde toprak serilerinin tüm karakteristiklerinin benzersiz bir varlık olarak kapsanması ve topraklarla ilgili bütün yorumlamalara 
olanak vermesidir. Araştırma alanında yapılan temel toprak etüt ve haritalama çalışmasında üç aşamada gerçekleştirilmiş̧ir. 1. Büro Çalışması olarak adlandırılan ilk aşamada temel kartografik materyal olarak Quickbird uydu görüntüleri kullanılmış, bu görüntülerin coğrafi düzeltmesi yapılmış, sınıflandırılmış, çalışma alanı sınırları arazi gözlemleri ile doğrudan uydu görüntüsü üzerine aktarılmıştır. Geçici toprak sınırlarını çizmek için farklı yeryüzü şekillerinin belirgin bir şekilde ayrılabildiği, arazi ve uydu görüntüsü yorumuna dayanan fizyoğrafik analiz yöntemini seçilmiştir. Ayrıca bu aşamada çalışma alanında var olan farklı toprak serilerini temsil edebilecek yerlerden, yeter sayıda profil çukurlarının (nokta) yerleri belirlenmiştir. 1. Arazi çalışması olarak isimlendirilen bu 2. aşamada belirlenen noktalarında bir kazıcı yardımıyla toplamda 11 adet profil çukurları açılmış bunlardan 8 tanesi farklı toprak serisi olarak tanımlanmıştır. Tanımlanan her bir profil çukuru horizon esasına göre seri düzeyinde Soil Survey Staff (1994)' e göre tanımlanarak isimlendirilmiştir. Birinci arazi çalışmaları aşamasında haritalama lejantı hazırlanmış, toprak serilerinin olası yayılım alanları da gözetilerek lejant için gerekli olabilecek bilgiler toplanmıştır. Toprak serilerinden horizon esasına göre alınmış toprak örnekleri analize hazırlanarak fiziksel ve kimyasal analizler için laboratuvara taşınmıştır. Toprak pH'sı 1:2,5 toprak:saf su karışımından pH metre ile (Nesmith, 1972), EC hazırlanan saturasyon çamurundan elektriksel iletkenliğinin ölçülmesiyle (U.S. Salinity Laboratory Staff, 1954), organik madde Allison (1965)'a göre, katyon değişim kapasitesi ve sodyum asetat ekstrasyonu yöntemi ile (U.S. Salinity Laboratory Staff, 1954), kireç Scheibler kalsimetresi ile (Schlichting ve Blume, 1966) ve toprak tekstürü Bouyoucos (1952) tarafindan esasları belirlenen hidrometre yöntemi ile belirlenmiştir.

Üçüncü ve son aşamada ise, sınıflandırılmış uydu görüntüleri üzerine yorumlama ile çizilen farklı toprak seri ve faz sınırları, arazide en fazla 400 metre aralıklarla $120 \mathrm{~cm}$ derinliğe kadar toprak burgusu kullanılarak kontrol edilmiştir. Arazi çalışmaları sonucunda kartografik mateyaller üzerine sınırlar çizilmiş ve sınırlar içerisindeki kalan alanları tanımlayan haritalama birimleri ArcGIS yazılımı yardımıyla bilgisayar ortamına aktarılmıştır. Bu aktarımda altlık olarak kullanılan Quickbird uydu verisi üzerine, toprak özelliklerini tanımlayan 327 adet haritalama birimi çizilmiştir. Tespit edilen toprak serileri dünyada yaygın olarak kullanılan Toprak Taksonomisi (Soil Survey Staff, 2014) ve FAO/UNESCO Dünya Toprak Haritası Lejandı (WRB, 2014) toprak sınıflama sistemleri kullanılarak sınıflamaları yapılmıştır.

Arazi ve toprakların sınıflandırılması işlemlerinin bir diğeri de Tarım Orman Bakanlı̆̆ı'nın halen uygulamakta olduğu ve 03.07.2005 tarihinde yürürlüğe giren 5403 sayılı Toprak Koruma ve Arazi Kullanımı Kanunu (TKAKK)'na göre olan sınıflandırmadır. Söz konusu bu kanunun 15.12.2005 tarih ve 26024 sayılı Resmi Gazetede yayımlanmış olan uygulama yönetmeliğinin öngördüğü hususlar esas almıştır. Oluşturulan detaylı toprak haritaları doğrultusunda ve Toprak Koruma ve Arazi kullanımı Kanunu ilgili uygulama yönetmeliğinin öngördüğü hususlara göre çalışma alanı Mutlak Tarım Arazisi, Marjinal Tarım Arazisi, Dikili Tarım Arazisi ve Diğer Araziler (Orman Alanı, Toprak Olmayan Alan ve Yerleşim Alanı) olmak üzere sınıflandırılmıştır.

$\mathrm{Bu}$ değerlendirme çalışmasının yanı sıra yapılan temel toprak haritaları ve mevcut arazi kullanım bilgileri de kullanılarak, alanın uluslararası bir sınıflama sistemi olan arazi yetenek sınıflaması (Klingebiel ve Montgomery, 1961) haritasında oluşturulmuştur. Temel toprak haritalarının toprak bilimi dışında uzmanlar tarafından da yorum ve kullanımını kolaylaştırmak için toprakların tarımsal ve tarım dışı amaçlı çeşitli kullanımlara uygunluğunun saptandığı ve sonuçta 1:25.000 ölçekli Potansiyel Arazi Kullanım ve Tarımsal Kullanıma Uygunluk Haritalarının hazırlandığı arazi değerlendirme çalışmaları yapılmıştır. Araştırma alanının arazi değerlendirmesi ve İdeal Arazi Kullanım Planlaması, FAO (1977) tarafından arazi değerlendirme çalışmalarında kullanılmak üzere yayınlanan ilkelerin, Şenol (1983), Şenol ve Tekeş (1995) tarafından Türkiye koşullarına uyarlanması sonucu geliştirilen ŞENOL Arazi Değerlendirme Sistemi ile yapılmıştır.

\section{Bulgular}

Araştırma alanında 5 ayrı fizyoğrafik birim üzerinde oluşmuş toplam 8 farklı toprak serisi tanımlanmıştır (Şekil 2). Bu toprak serilerinden Mustafalar, Garipçe ve Sarıçam serileri yaşlı deniz terasları, Yaylapınar ve Zeytinlik serileri vadi tabanlarında, Çeşme serisi kil taşı ana materyali üzerinde, Kılıçlı serisi alüviyal taban arazide, Kesmelik serisi marn ana materyali üzerinde 
tanımlanmışlardır. Serilerin alansal dağılımları ve Soil Taxonomy ve World Referance Base (WRB) sınıflandırma sistemlerine göre hangi sınıflara dahil oldukları Çizelge 1.'de verilmiştir.

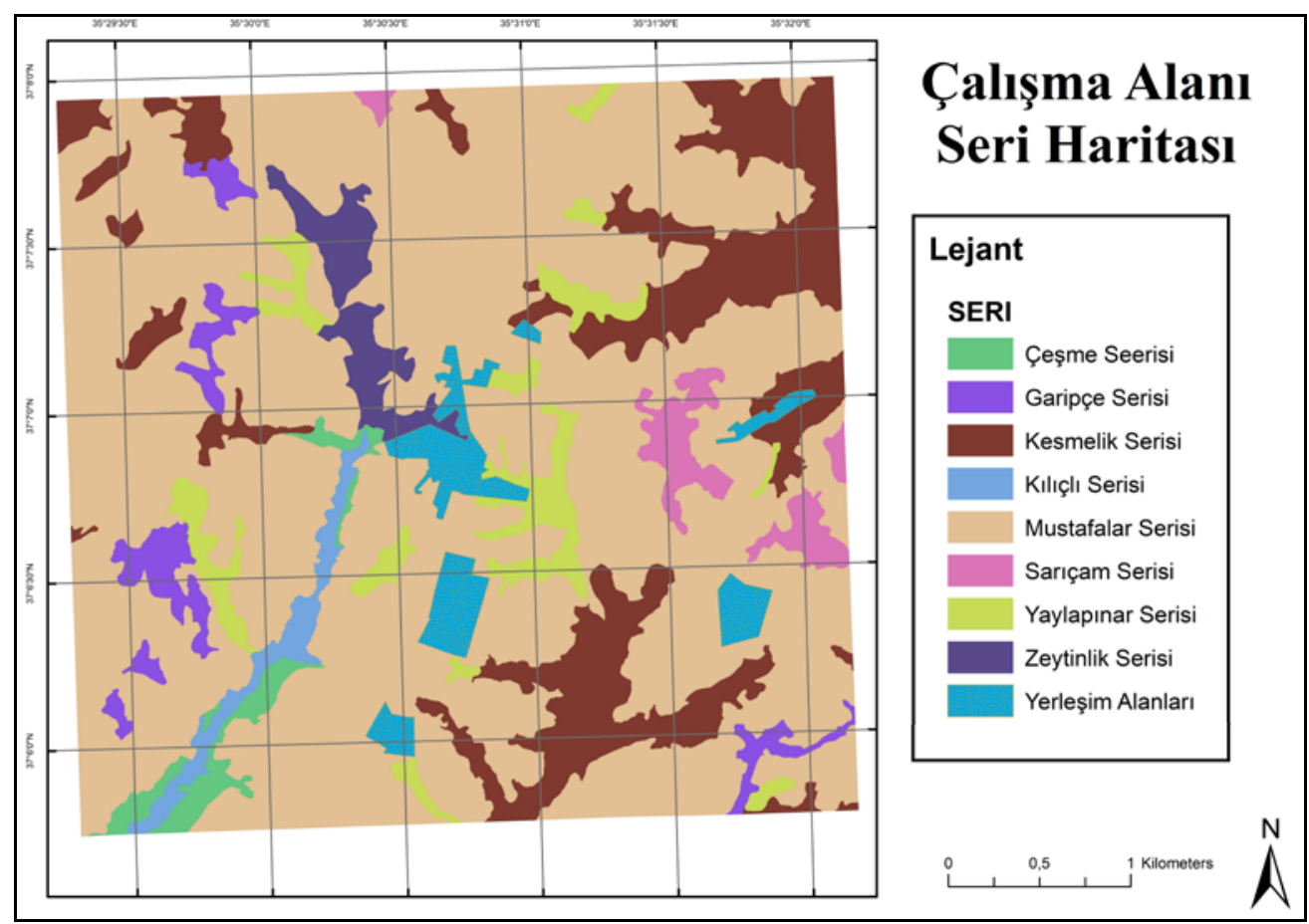

Şekil 2. Çalışma alanı seri haritası

Çizelge 1. Çalışma alanı toprak serileri dağılımı ve sınıflandırmalar|

\begin{tabular}{|c|c|c|c|c|}
\hline Seri Ad1 & \multicolumn{2}{|c|}{ Alansal Dağılımı } & Soil Taxonomy & WRB \\
\hline & ha & $\%$ & & \\
\hline Sarıçam & 33.81 & 2.02 & Calcic Haploxeralf & Calcic Luvisol \\
\hline Garipçe & 43.28 & 2.58 & Typic Calcixerepts & Haplic Calcisol \\
\hline Mustafalar & 1197.56 & 71.41 & Petrocalcic Calcixerepts & Haplic Regosol \\
\hline Kesmelik & 234.36 & 13.98 & Calcic Haploxerepts & Haplic Regosol \\
\hline Yaylapinar & 76.6 & 4.57 & Typic Xerofluvent & Calcaric Fluvisol \\
\hline Zeytinlik & 46.2 & 2.76 & Typic Xerofluvent & Calcaric Fluvisol \\
\hline Çeșme & 20.45 & 1.22 & Vertic Xerofluvent & Calcaric Fluvisol \\
\hline Kilıçlı & 1.47 & 24.65 & Vertic Xerofluvent & Calcaric Fluvisol \\
\hline
\end{tabular}

Çalışma alanı topraklarının \%61.02'si çok sı̆̆ $(0-30 \mathrm{~cm}), \% 25.55$ 'i sı̆̆ $(30-60 \mathrm{~cm}), \% 9.03$ 'ü derin $(60-90 \mathrm{~cm}), \% 1.40$ ' 1 çok derin $(>90 \mathrm{~cm})$ olarak tespit edilmiştir. Arazinin \%52.15'lik kısmında eğim \%0-2 arasında iken \%40.21'lik alanında \%2-6 arasında ve \% 7.64 'lük alanda \%6'dan fazla olarak tespit edilmiştir. Üst toprak tekstürü genellikle hafif ve orta bünyeli olması nedeniyle tohum çimlenmesinde ve çıkışında sorun yaratmayacağı öngörülürken, \%18,96 oranındaki alanda görülen siltli killi tın üst toprak tekstürün bulunduğu topraklarda görülebilecek kaymak tabakası oluşumuna dikkat edilmesi gerekmektedir. Araştırma alanı topraklarını \% 61'i en fazla $30 \mathrm{~cm}$ derinliğe sahip olduğundan, derin köklü bitkilerin yetiştiriciliğini engellemektedir. Özellikle çalışma alanın topraklarının \%48'inin eğimli ya da çok dik eğimli olduğu da düşünülürse, yanlış yapılacak olan amenejman tekniklerinin toprağın erozyonla kayıp olmaması için doğru uygulamalar yapmak sürdürülebilir üretim faaliyetleri için bir zorunluluk haline gelmiştir.

Yapılan fiziksel ve kimyasal analiz sonuçlarına göre; çalışma alanı topraklarının pH değeri 7.42-8.15 arasında olup reaksiyonları hafif-kuvvetli bazik arasında değişmektedir. Genel olarak yüksek miktarda kireç içermesi $\mathrm{pH}$ değerlerinin 7'nin üzerinde ölçülmesine sebep olmuştur. Aynı zamanda bu topraklardaki pH'nın 8.5 üzerinde ölçülmemesinin sebebi olarak da değişebilir $\mathrm{Na}$ içeriğinin yüksek olmamasıdır. Buradan hareketle çalışma alanı topraklarında yapılacak olan tarımsal 
üretimlerde pH'nın sınırlayıcı bir faktör olarak yer almayacağ 1 anlaşılmıştır. Kireç içeriği incelendiğinde, toprakların büyük çoğunluğunun çok yüksek kireç içeriğine sahip oldukları görülmektedir. Ortalama kireç içeriği en düşük ( \% 19.6 ) olan toprak serisi Sarıçam serisi, en yüksek olan toprak serileri ise değerleri birbirine çok yakın olan Kesmelik (\% 57.6) ve Zeytinlik (\% 57.8) serileri olarak belirlenmiştir. Çalışma alanının büyük kısmında yayılım gösteren kireç içeriği yüksek topraklar, tarımsal üretim açısından kirece dayanıksız olan bitkiler için sorun olabilecek seviyededir. Ancak çalışma alanı için önerilen arazi kullanım türlerinden İncir, Zeytin, Soğan, Sarımsak, Buğday, Pamuk ve Ayçiçeği gibi kirece dayanıklı bitkiler için sorun teşkil etmeyeceği öngörülmüştür. Çalışma alanında yer alan toprak serilerinin hiçbirinde önemli düzeyde tuzluluk sorunu tespit edilmemiştir. Organik madde içeriği \% 1.06 ile \% 1.90 arasında değişmektedir. Araştırma alanı topraklarında tarımsal üretimde fark yaratabilmek için toprakların organik maddece zenginleştirilmesi gerekmektedir. Genellikle kil tekstüre sahip çalışma alanı toprakları bazı arazi kullanım türleri için ciddi sorun oluşturabilecektir. Tercih edilecek olan tarımsal ürün çeşitlerinin daha çok ağır bünyeli topraklara adapte olabilecek ürünler olmasına dikkat edilmesi gerekmektedir. Katyon Değişim Kapasitesi (KDK) değerleri 11.60 me/100 gr ile 38.50 me/100 gr arasında değişmektedir. En yüksek KDK değerlerine, Sarıçam serisinin Btss horizonlarında rastlanmıştır. Çalışma alanının en ince bünyeli toprak serisi Çeşme serisi olup, bu toprak serisinde kil içeriği \% 52.5 ile \% 75 arasında değişmektedir.

Yapılan arazi yetenek sınıflaması sonucunda ise \%1.64'lik alan II. Sınıf, \%10.89'luk alan III. Sınıf, \%32.11'lik alan IV. Sınıf ve \%55.36'lık alan VI. Sınıf olarak tespit edilmiştir (Şekil 3). Yapılan arazi değerlendirmeleri sonucunda araştırma alanı arazilerinin büyük bir bölümünün eğimli ve/veya toprak derinliğinin sı ̆ ya da çok sı ̆̆ olmasından dolayı çalışma alanının \%12.54'ünü II. ve III. sınıf araziler oluşturmaktadır. Bu denli az miktardaki verimli alanlarda tercih edilecek olan arazi kullanım türü mutlak suretle tarımsal ürün yetiştiriciliği olmalıdır. Aksi halde yöredeki üretim potansiyelinin en yüksek olduğu topraklar uygun şekilde yönetilememiş olacaktır. Yaklaşık 538 ha olarak tespit edilen IV. sınıf arazilerde devamlı olarak çayır-mera kullanımına uygundur. Bu sınıf arazilerde de kısmen tarla bitkileri yetiştiriciliği yapılabileceği gibi bu üretim modelini eğim, derinlik ve kısmen de taşlılık tarımsal faaliyetleri sınırlar niteliktedir. Yine bu sınıf içindeki alüviyal taban arazilerde ağır bünyeli toprak profilleri bitki yetiştiriciliğinde sorun oluşturabilecektir. Araştırma alanında \%55'lik bir alanda bulunan VI. sınıf arazilerde eğimli, erozyon riskine maruz kalabileceğinden dolayı orman veya mera olarak kullanımında dahi dikkat edilmeli ya da tedbirler alınmalıdır.

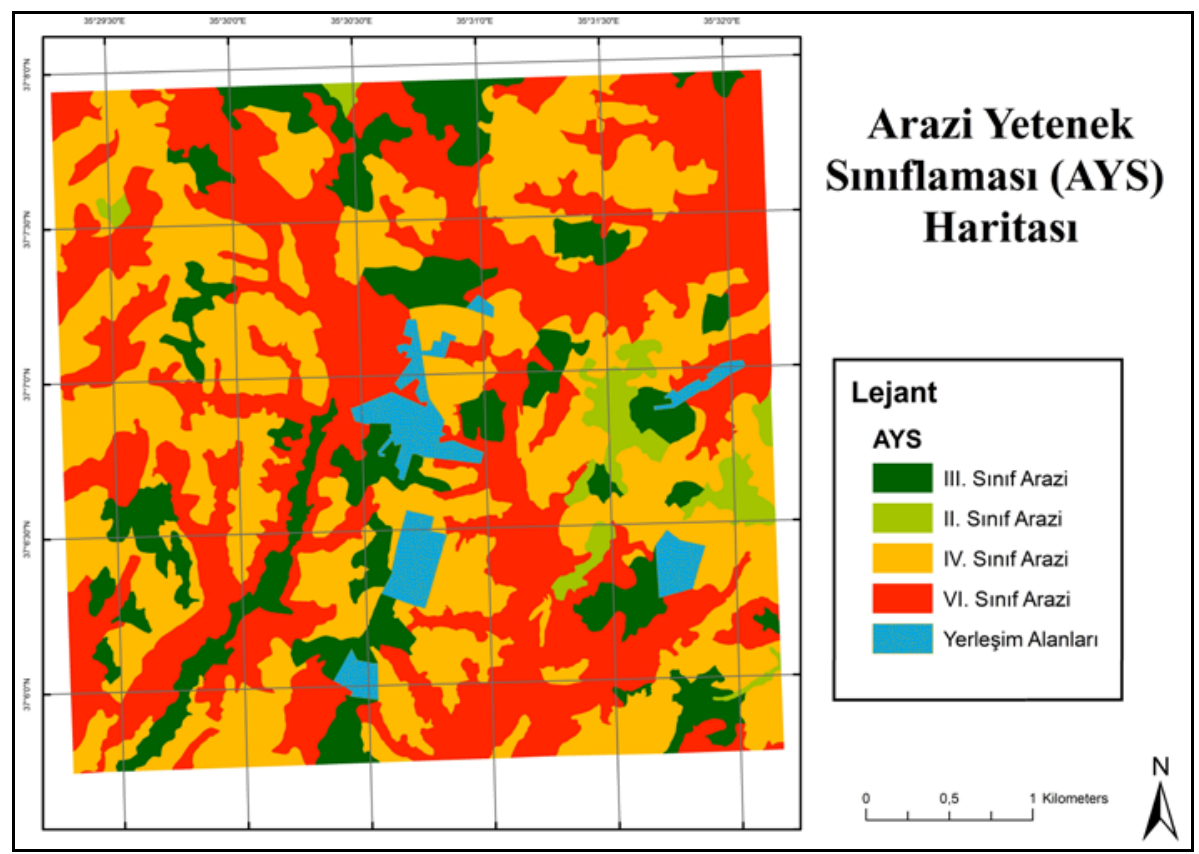

Şekil 3. Çalışma alanı Arazi Yetenek Sınıflaması (AYS) hartası. 
Çalışmanın arazi değerlendirme çalışmalarından birisi de 5403 sayılı Toprak Koruma ve Arazi Kullanım Kanuna (TKAKK) göre yapılan arazi değerlendirme çalışmasıdır. Bu çalışmada arazilerin mevcut durumları da dikkate alınarak sınıflama yapılmış gelecekte yapılacak olan çalışmalarda hangi arazilerin hangi uygulamalar için uygun olabileceğinin altlığı verilmiştir. Çalışma alanında TKAKK'a göre sınıflandırılmış arazilerin alanları, toplam alana oranları Çizelge 2'de ve ilgili alan dağılımlarının haritası ise Şekil 4'de verilmiştir. Hali hazır orman arazilerinin çalışma alanında önemli bir yer (\%27.3) kaplamasının yanı sıra arazideki bazı toprak ve topografik sınırlamalar nedeniyle üzerinde sadece geleneksel toprak işlemeli tarımın yapıldığı marjinal tarım arazileri çalışma alanının \%51'ini oluşturmaktadır. Çalışma bölgesinde yapılan tarımsal faaliyetler genellikle kuru tarım ya da tek yıllık bitki yetiştiriciliğgi olduğu için dikili tarım yapılan alanlar (\% 6.9) kısıtlı kalmıştır. Buna sebep olarak da çalışma alanının \% 86.5'inin toprak derinliğinin çok sığ veya sı̆̆ olmasıdır. Ana kayanın yüzeye çıkması ya da malzeme alınması nedeniyle üzerinde tarımsal bir faaliyet yapabilmek için yeterli toprağın bulunmadığ toprak olmayan arazi miktarı (\% 1.2) ve yerleşim yerlerinin kapladığı alanların (\% 3.2) henüz çok fazla olmaması, bu araziler için yapılan kullanım planlaması çalışmalarının gerekliliğini bir kez daha ortaya koymaktadır.

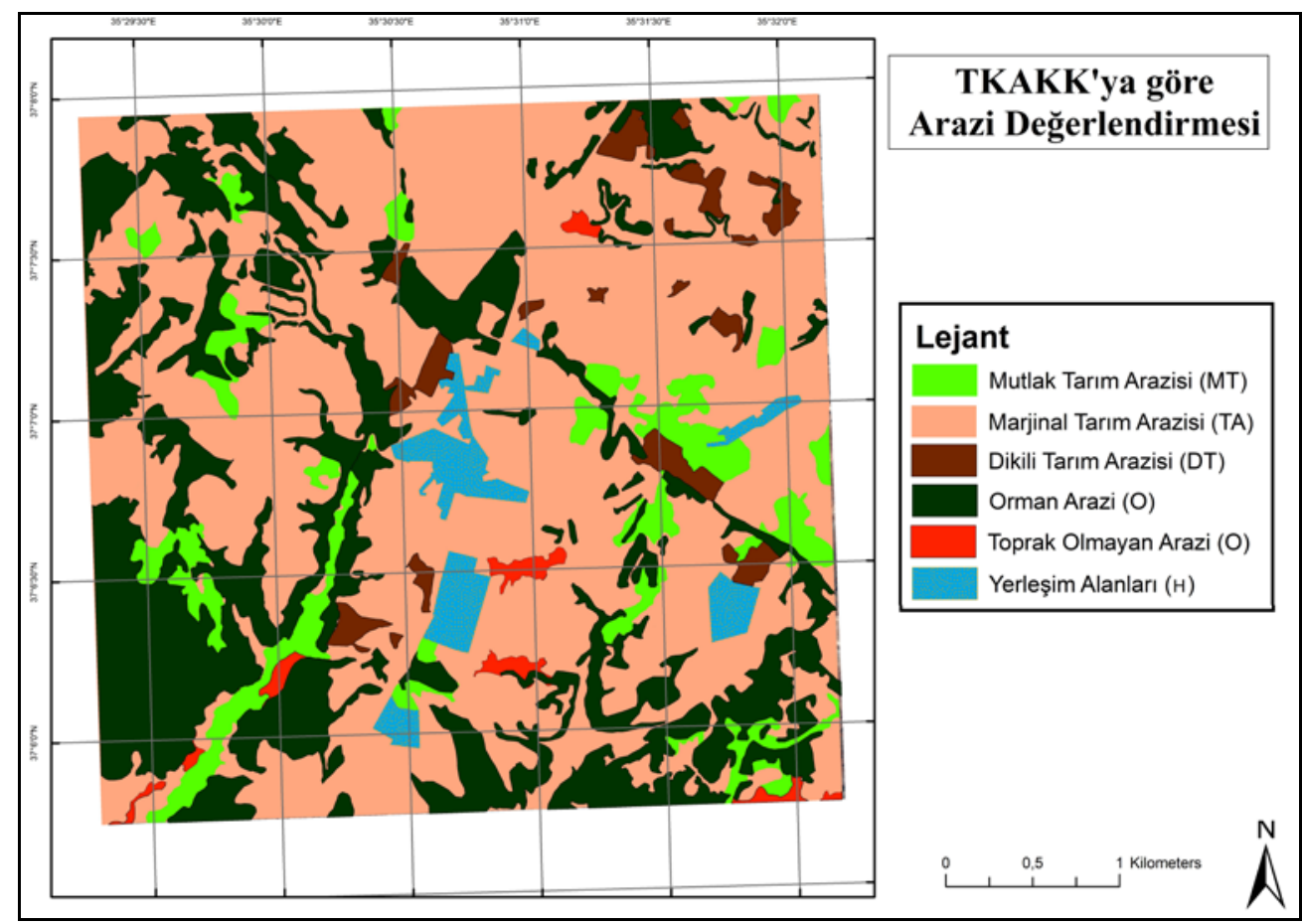

Şekil 4. Çalışma alanı TKAKK'ya göre arazi sınıflaması haritası.

Çizelge 2. Çalışma alanında TKAKK'a göre sınıflandırılmış arazilerin toplam alana oranları

\begin{tabular}{|c|c|c|c|}
\hline TKAKK Sinıfi & & Alan (ha) & Toplan Alana Oranı \\
\hline Mutlak Tarım Arazisi & & 179.8 & 10.4 \\
\hline Marjinal Tarım Arazisi & & 883 & 51 \\
\hline Dikili Tarım Arazisi & & 119.1 & 6.9 \\
\hline \multirow[t]{3}{*}{ Diğer Tarım Arazileri } & Orman & 473.3 & 27.3 \\
\hline & Toprak Olmayan & 20.6 & 1.2 \\
\hline & Yerleşim Alanlart & 56.1 & 3.2 \\
\hline
\end{tabular}

Bütün bu çalışmaların sonucunda çalışma alanı arazileri için gelecek yıllar içerisinde gerçekleşebilecek olan nüfus artışı ve kentsel alan ihtiyacını karşılamak üzere 1., 2. ve 3. Aşama arazi kullanım önerisi haritaları oluşturulmuştur. Bu kullanım önerileri yörenin iklimsel faktörleri de göz önünde bulundurularak öncelikle arazi yetenek sınıfı, toprak derinliği ve eğim gibi özellikleri de incelenerek oluşturulmuş bir yorum haritası niteliğindedir. Tarımsal Kullanım, Tarım Dışı Kullanım, 
Halihazır Orman Alanları ve Halihazır Yerleşim Alanları olmak üzere 4 farklı arazi kullanım modeli önerilmiştir. Hali hazırdaki orman arazilerinin mutlak koşulda orman kalması yalnızca 6831 sayılı Orman Kanunu ve 5403 sayılı Toprak Koruma ve Arazi Kulanım Kanunu kapsamında farklı bir kullanıma izin verilmesi önerilmiştir. Aynı şekilde çalışma alanında bulunan yaklaşık 21 ha'lık bir alanda bulunan Zeytinlik arazilerde ayrıca değerlendirilmiş, 3573 Sayılı Zeytin Kanununu kapsamında kullanıcıların tasarrufunda olması önerilmiştir.

1. Aşama Arazi Kullanımı Öneri haritasında mevcut yerleşim alanlarına ek olarak ihtiyaç olabilecek kentsel ve sanayi yerleşim alanları için gerekli yerler Tarım Dışı Kullanım alanı için önerilmiştir (Şekil 5). Bu alanlar belirlenirken Eğim, Derinlik, Arazi Yetenek Sınıfı dikkate alınıp bunların korelasyonu sonucu en verimsizler Tarım Dışı olarak önerilmiştir.

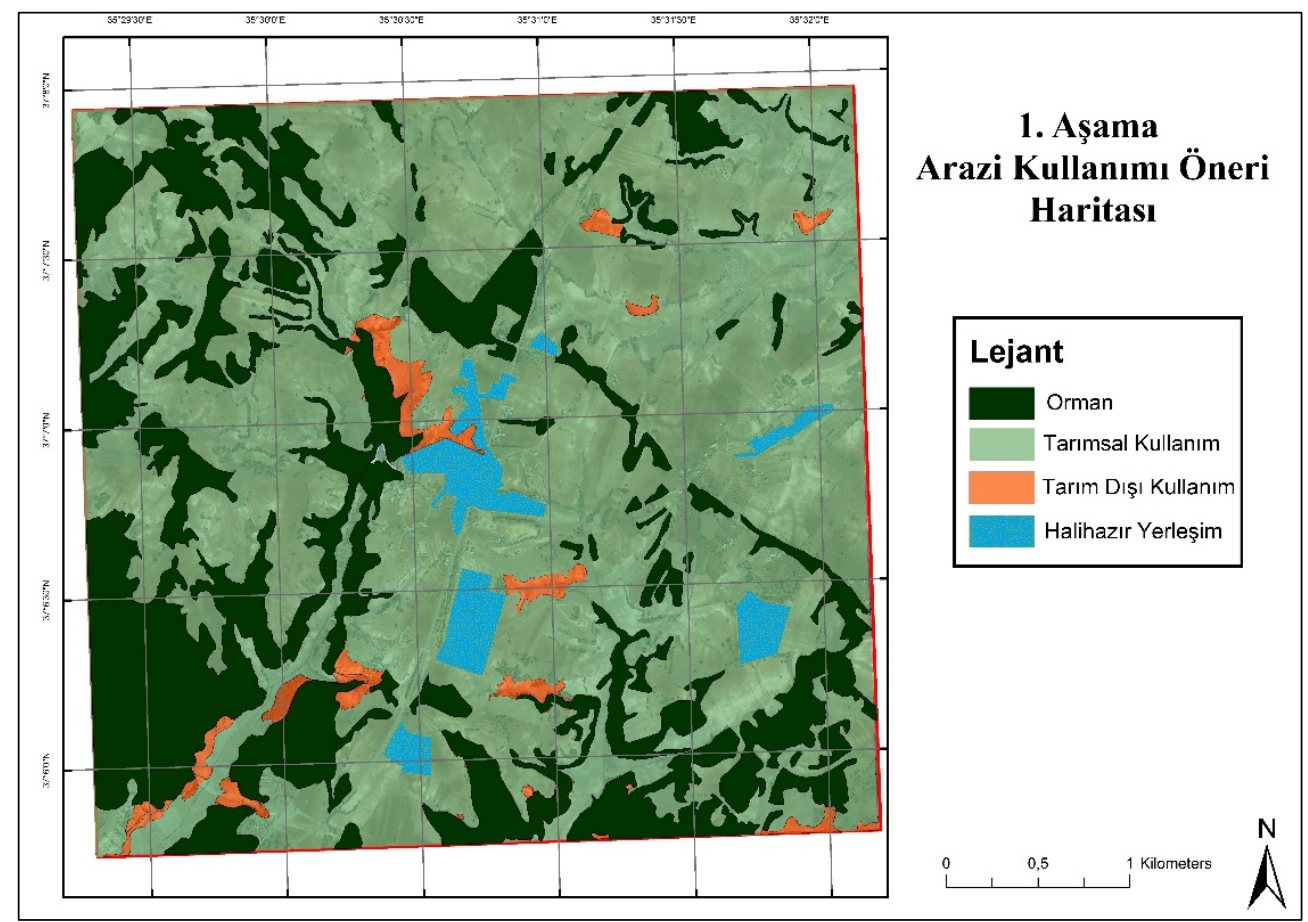

Şekil 5. 1.aşama arazi kullanımı öneri haritası.

2. aşama arazi kullanımı öneri haritası 1.aşamada tarım dışı kullanılabileceği önerilen arazilerin tamamının kullanılması ve buna rağmen tarım dışı arazi ihtiyaçların halen devam etmesi durumunda kullanılabilecek bir öneri haritasıdır (Şekil 6). Bu aşamada da yine bir önceki arazi kullanımı öneri haritasında olduğu gibi mevcut orman alanlarının korunmasının devamlılığı sağlanmıştır. 1.aşamadaki tarımsal alan olarak önerilen ancak toprakların eğim, derinlik ve taşl1lık özellikleri bakımından en az yetenekli olanların tarım dışı olarak kullanılabileceği tavsiye edilmiştir. 1 . aşamadan faklı olarak eğimi $\% 2-6$, derinliği $0-30 \mathrm{~cm}$ ve yüzey taşlılığı $\% 15$ 'den az olan araziler 2.aşamada tarım dışı kullanımı önerilen araziler olmuştur. 


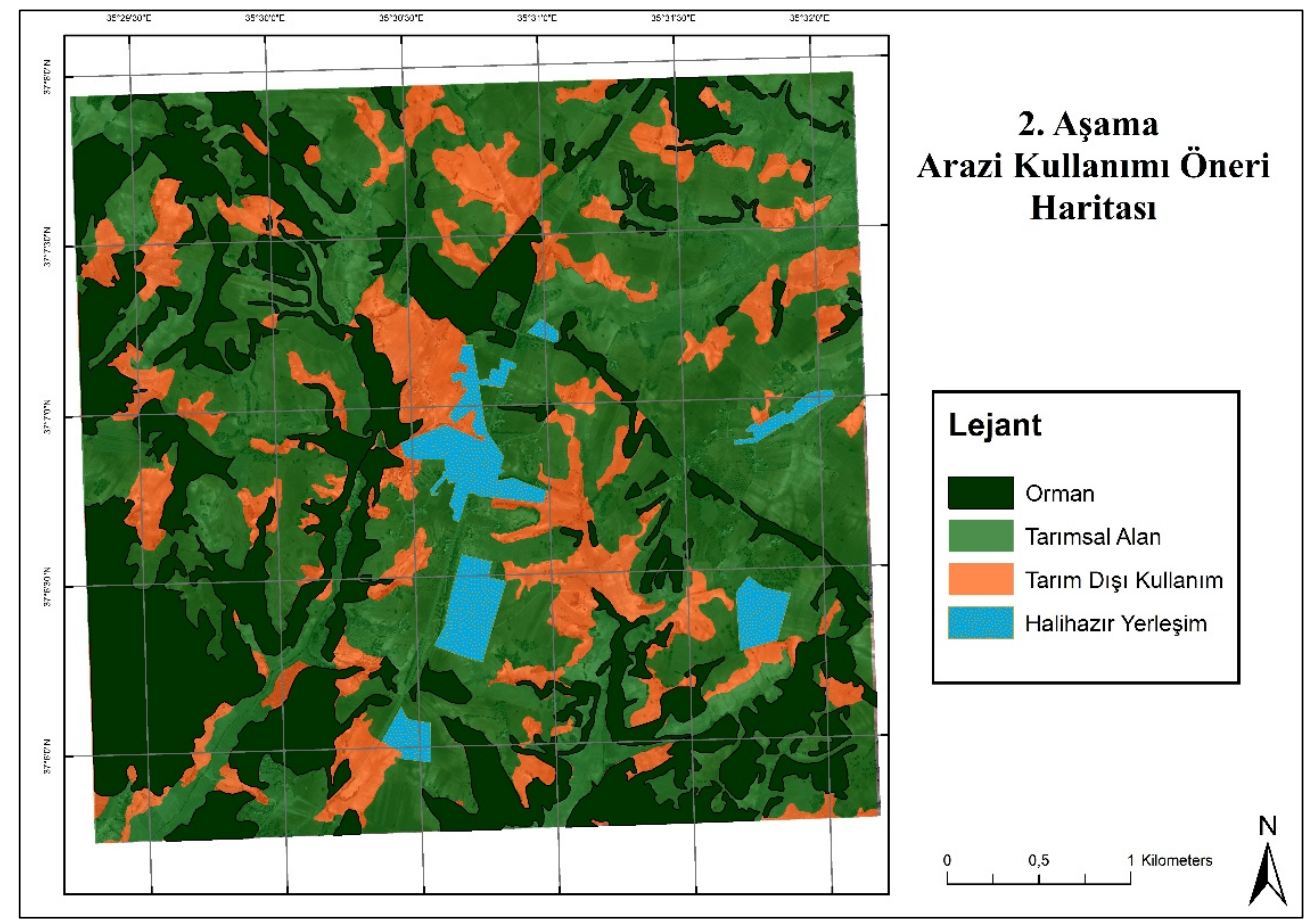

Şekil 6. 2. aşama arazi kullanımı öneri haritası.

3. aşama arazi kullanım haritasında da yine mevcut orman varlıkları korunmak suretiyle öneride bulunulmuştur. Bu aşamada 2.aşamadan farklı olarak eğimi \%0-2 arasında olmasına rağmen derinliği $30 \mathrm{~cm}$ 'den az olan toprakların bulunduğu arazilerin tarım dışı olarak kullanılabileceği önerilmiştir (Şekil 7). Öneri haritalarında Tarım Dışı Kullanım olarak sınıflandırılan alanlar hali hazırda tarımsal olarak kullanılmaktadır. Ancak ileride doğabilecek Kentsel ve/veya Sanayi alanları için kullanılması gereken alanların öneri haritalarında belirlenen yerler olmasına dikkat edilmesi gerekmektedir. Aksi bir durumda yani Kentsel ve/veya Sanayi alanı ihtiyaç olmaması halinde Tarım Dışı Kullanım önerisi yapılan arazilerde hali hazır kullanımlarının devam etmesinde hiçbir sakınca bulunmamaktadır.

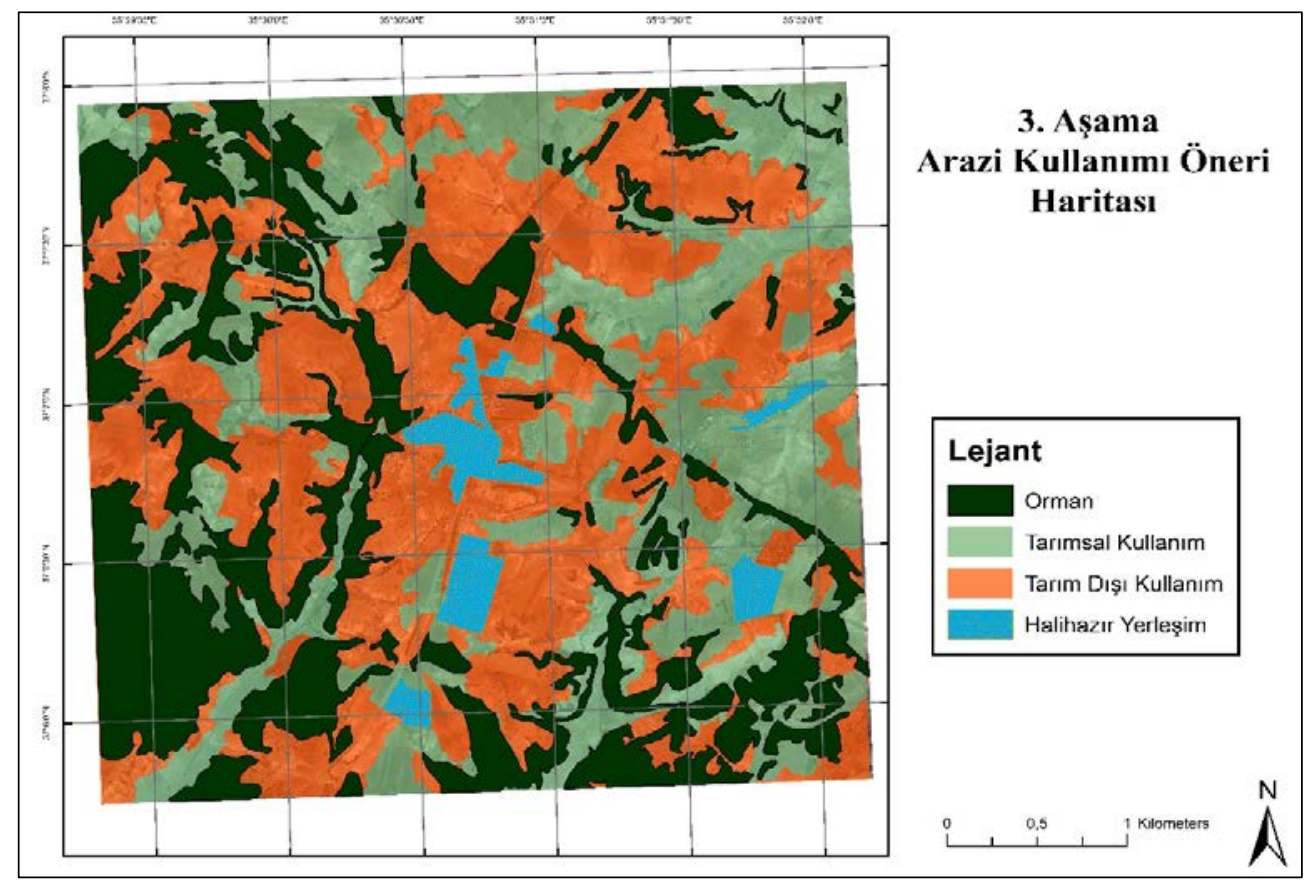

Şekil 7. 3.aşama arazi kullanımı öneri haritası. 


\section{Tartışma ve Sonuç}

Adana ilinin sulu tarıma açıldığı süreden bu zamana kadar ki geçen süreçte tarımsal verimliliği yüksek olan birçok arazi yerleşim alanı veya sanayi alanı olarak, birçok mera ve orman alanı ise tarımsal alana dönüştürülmüştür. Verimli tarım alanlarının daralmasıyla başta doğal tahribat olmak üzere, çevre kirliliği ve alt yapı sorunlarına da neden olmaktadır. Tarım arazilerinin bu derece hızlı bir şekilde tahrip olduğu Adana ilinde geride kalan verimli arazileri doğru bir yönetim şekliyle gelecek nesillere miras bırakılabilmelidir. Yapılan bu çalışmada Adana'da günümüzde kentsel gelişimin yöneldiği alanların içerisinde bulunan Sarıçam ilçesine bağlı Mustafalar köyünde detaylı toprak etüt haritalaması yapılarak ideal ve potansiyel arazi kullanım planları oluşturulmuştur. Bu planlamalar doğrultusunda geleceğe yönelik planlamalara altlık olabilecek tematik haritalar üretilerek yeni kullanım yöntemlerinin geliştirilmesi üzerinde önemli bulgular elde edilmiştir. Hâlihazır haritalar ve TKAKK sınıflandırması sonrası oluşan haritalarının karşılaştırılması sonucunda hâlihazır haritada tespit edilen Orman ve Tarımsal alanlar TKAKK' nun önerdiği orman ve tarımsal alanlardan çok daha fazladır. $\mathrm{Bu}$ da etüt alanında henüz tarımsal alanların yerini kentsel alanların, ormanların yerini de tarımsal alanların almadığını göstermektedir. Bu sebeple kentleşme ve sanayileşme potansiyeli yüksek olan Mustafalar köyünde arazi kullanım önerileri dikkate alınmalı, araziler maksimum faydayı sağlayacak şekilde ve yeteneğine uygun olarak yönetilmelidir.

\section{Teșekkür}

Bu çalışama Çukurova Üniversitesi BAP Birimi tarafından desteklenmiştir.

\section{Kaynakça}

Abdelrahman, M.A., Natarajan, A. \& Hegde, R. (2016). Assessment Of Land Suitability And Capability By Integrating Remote Sensing And Gls For Agriculture In Chamarajanagar District, Karnataka, India. The Egyptian Journal Of Remote Sensing And Space Science, 19(1), Pp.125-141.

Allison, L.E. (1965). Organic Carbon In Methods Of Soil Analysis. (Editor: Black, C.A.). Amer. Soc. Agron. Mon. 9. Madison, Wis

Akten, M. (2008). Isparta Ovasının Optimal Alan Kullanım Planlaması Üzerine Bir Araştırma. Doktora Tezi, Süleyman Demirel Üniversitesi Orman Mühendisliği Anabilim Dalı Isparta, Türkiye

Bouyoucus, G.J. (1951). A recalibration of the hydrometer method for making mechanical analysis of soils. Agronomy Journal, 43, 434-438.

Çelik, A., \& Akça, E. (2017). Adıyaman'da eğimli akarsu seki topraklarının sürdürülebilir kullanımı için öneriler. Yüzüncü Y1l Üniversitesi Tarım Bilimleri Dergisi, 27(1), 130-141.

Çullu, M.A. (2012). Toprak Etüt Haritalama ve Toprak Yönetimi Gerekliliği. Toprak Bilimive Bitki Besleme Dergisi. Vol.1 Sayı 1, Ss. 23-25

FAO. (1976). A Framework For Land Evaluation. Fao Soils Bulletin No.32, Rome.

FAO. (1977). A Framework for Land Evaluation, International Institute For Land Reclamation And Improvement/Ilr1, Publication 22, Wageningen, The Netherlands, 87 P.

FAO-UNESCO. (1990). Soil Map of the World. Revised Legend. World Soil Resource Report 60. Rome.

Klingebiel, A.A. \& Montgomery, P. H., 1961. Land Capability Classification. Agricultural Handbook 210. Soil Conservation Service, US Gov. Print. Office, Washington DC.

Nesmith, W.E.J., Geraldson, C.M. \& Woltz, S.S., (1972). The interpratation of soluble salt test and soil analysis by different procedures. Florida Flower Grower, 9(4), 5.

Schlichting, E. \& Blume, E. (1966). Bodenkundliches Praktikum. Verlag Paul Parey, Hamburg Und Berlin: Preis: Kartoniert

Soil Survey Staff (1993). Soil Survey Manual., United States Department Of Agriculture, Handbook No.18.

Soil Survey Staff. (1998). Keys to Soil Taxonomy. Natural Resources Conservation Service, Eighth Edition. USDA, Washington D.C. 
Solmaz, M. İsmail, \& Şenol, S. (2010). Eğimli arazilerin detaylı toprak etüd ve haritalanması için uzaktan algılama ve coğrafi bilgi sistemleri teknolojilerini kullanarak yeni yöntemlerin geliştirilmesi

Sönmez, M. E. (2011). Adana şehrinin alansal gelişimi ve yakın çevresinin arazi kullanımında meydana gelen değişimler. Türk Coğrafya Dergisi

Şenol, S. (1983). Arazi Toplulaştırma Çalışmalarında Kullanılabilir Niceliksel Yeni Bir Arazi Dereceleme Yönteminin Geliştirilmesi Üzerine Araştırmalar. Ç.Ü. Fen Bilimleri Enstitüsü, Doktora Tezi, Adana, 122s.

Şenol, S. (1994). Bilgisayar destekli bir model yardımıyla göksu deltası topraklarının tarımsal kullanıma uygunluk sinıflamas1. Turkish Journal of Agriculture and Forestry, 18(5), 437-443.

Şenol, S. \& Tekeş, Y. (1995). Arazi Değerlendirme ve Arazi Kullanım Planlaması Amacıyla Geliştirilmiş Bir Bilgisayar Modeli. Türkiye toprak ilmi derneği, ilhan akalan toprak ve çevre sempozyumu, Yayın No:7, Cilt 1, 204-210.

Şenol, S., Aksoy, E., Çullu, M.A., Bayramin, İ., Kılıç, Ş., Dingil, M., Koca, Y.K. (2010). Türkiye’de Toprak Koruma ve Arazi Kullanım Kanunu Gereği Yapılması Zorunlu Toprak Etüdleri ve Önemi. Ziraat Mühendisliği Vı1 Teknik Kongresi, Ankara, Türkıye, 11-15 Ocak 2010, Cilt.1, Ss.59-71

Tarım Orman Ve Köyişleri Bakanlığı. (1996). Adana İli Arazi Varlı̆̆ Raporu ve Haritası. Köy Hizmetleri Genel Müdürlüğü Yayınları. İl Rapor No:1, Ankara

Topçu, P. (2012). Tarım Arazilerinin Korunması ve Etkin Kullanılmasına Yönelik Politikalar Uzmanlık Tezi. Kalkınma Bakanlığı Yayın No: 2836

U.S. Salinity Laboratory Staff. (1954). Diagnosis and Improvement of Saline and Alkali Soils. Editor: Richards, L.A., Usda Agriculture Handbook. No: 60, Us: Goverment Print Office, Washington D.C. USA.

Worldometers. (2016). Countries in the world by population. https://www.worldometers.info/ Erişim tarihi: 16.06.2016.

Yakar, A. (2013). Kentsel Gelişme Alanlarında Arazi Kullanımı Ve Değişiminin Sürdürülebilir Arazi Yönetimi Açısından İncelenmesi: Trabzon İli Örneği. KTÜ Fen Bilimleri Enstitüsü Yüksek Lisasns Tezi. 